\title{
Natural Wolframite Used as Cathode Photocatalyst for Improving the Performance of Microbial Fuel Cells
}

\author{
Junxian Shi ${ }^{1}$, Anhuai $\mathrm{Lu}^{2}$, Haibin Chu ${ }^{3}{ }^{1}$, Hongyu $\mathrm{Wu}^{1}$ and Hongrui Ding ${ }^{2, *}$ \\ 1 Ministry of Education Key Laboratory of Ecology and Resource Use of the Mongolian Plateau \& Inner \\ Mongolia Key Laboratory of Grassland Ecology, School of Ecology and Environment, Inner Mongolia \\ University, Hohhot 010021, China; 111969116@imu.edu.cn (J.S.); 31815099@imu.edu.cn (H.W.) \\ 2 The Key Laboratory of Orogenic Belts and Crustal Evolution, School of Earth and Space Sciences, \\ Peking University, Beijing Key Laboratory of Mineral Environmental Function, Beijing 100871, China; \\ ahlu@pku.edu.cn \\ 3 School of Chemistry and Chemical Engineering, Inner Mongolia University, Hohhot 010021, China; \\ chuhb@imu.edu.cn \\ * Correspondence: DHR@pku.edu.cn
}

Received: 1 November 2018; Accepted: 4 December 2018; Published: 5 December 2018

\begin{abstract}
Developing simple and cheap electrocatalysts or photocatalysts for cathodes to increase the oxygen reduction process is a key factor for better utilization of microbial fuel cells (MFCs). Here, we report the investigation of natural wolframite employed as a low-cost cathode photocatalyst to improve the performance of MFCs. The semiconducting wolframite was characterized by scanning electron microscopy (SEM), X-ray diffraction (XRD), and Raman spectroscopy. The band gap and photo respond activities were determined by UV-vis spectroscopy and linear sweep voltammetry (LSV), respectively. Compared with the normal graphite cathode, when MFCs were equipped with a wolframite-coated cathode, the maximum power density was increased from $41.47 \mathrm{~mW} \cdot \mathrm{m}^{-2}$ to $95.51 \mathrm{~mW} \cdot \mathrm{m}^{-2}$. Notably, the maximum power density further improved to $135.57 \mathrm{~mW} \cdot \mathrm{m}^{-2}$ under light irradiation, which was 2.4 times higher than with a graphite cathode. Our research demonstrated that natural wolframite, a low-cost and abundant natural semiconducting mineral, showed promise as an effective photocathode catalyst which has great potential applications related to utilizing natural minerals in MFCs and for environmental remediation by MFCs in the future.
\end{abstract}

Keywords: microbial fuel cells (MFCs); natural wolframite; photocatalyst; wastewater treatment

\section{Introduction}

Microbial fuel cells (MFCs) are a famous device and have received considerable attention in recent years because of their great potential in alternative energy generation, wastewater treatment, and environmental monitoring [1-5]. The performance of MFCs is influenced by many factors, including electrode material, electricigens, equipment configuration, and so on. Because the most widely used cathode electron acceptor is oxygen, the cathodic oxygen reduction reaction is always a key limiting factor for MFCs [3-5]. So far, a variety of electrocatalysts and photocatalysts have been synthetized and utilized in MFCs to improve cathodic reactivity. Platinum has high catalytic activity and is the most commonly used catalyst, but its scarcity and high cost poses an obstacle for application in MFCs [6]. Thus, metal-free carbon materials and non-precious metal-based catalysts have been extensively investigated, and are often chosen as affordable alternatives to Pt-based catalysts [7-11]. For example, nitrogen-doped carbon nanotubes/graphene, Co-naphthalocyanine (CoNPc), pyrolyzed iron ethylenediaminetetraacetic acid-modified activated carbon, and a Co porphyrinylene-ethynylene framework have been studied [7-11]. Although the performance of MFCs could be remarkably 
enhanced, these catalysts still cannot be used widely owing to the complicated synthesis conditions and extra cost for high temperature and special inert atmosphere [10,11]. Moreover, the utilization of biocathodes is known as an alternative to noble/non-noble metal cathode catalysts in recently studies [12,13]. Unfortunately, the bacterial electron-transfer process in the cathode was unstable and their mechanisms have not been fully understood, and more significant research is required for their economic development and practical application.

It is commonly known that MFCs are developed on the basis of the extracellular electron transfer (EET) process of microorganisms. Iron and manganese oxide minerals serve as the most common natural electron acceptors for EET in natural environments $[4,5,14]$. Inspired by nature, some simple metal oxides have been used for cathode catalysts, including $\mathrm{MnO}_{2}(\alpha, \beta$, and $\gamma), \mathrm{TiO}_{2}$, and $\mathrm{PbO}_{2}$ [15-18]. After using these simple metal oxides, the performance of MFCs was increased, but these materials still waste some chemical reagents during their synthesis processes. It is worthwhile mentioning that Ren et al. first investigated the utilization of natural hematite as a cathode catalyst in a traditional MFC, which indicated that the maximum power density in a hematite-coated cathode MFC was 2.2 times higher than that in a graphite cathode MFC, and a current density of $330.66 \mathrm{~mA} \cdot \mathrm{m}^{-2}$ was stabilized over 10 days [19]. Shi et al. studied the performance and $\mathrm{Cr}(\mathrm{VI})$ removal efficiencies by natural pyrrhotite-coated cathode MFCs and demonstrated that the natural pyrrhotite not only played the role of catalyst, but also acted as a reactive site for $\mathrm{Cr}(\mathrm{VI})$ reduction [20]. It must also be mentioned that $\mathrm{Lu}$ et al. used the semiconducting mineral natural rutile as a novel photocathode catalyst for MFCs, which produced a maximal power density of 7.64 and $12.03 \mathrm{~W} \cdot \mathrm{m}^{-3}$ under dark and light irradiation, and provided a cost-effective alternative photocatalyst from nature [21]. With the help of natural semiconducting rutile, photocatalytic technology was successfully combined with MFC technology.

As we all know, sunlight sustains the processes of all life, and is the most important energy source on Earth. This renewable and clean solar energy can be utilized by semiconductor photocatalytic technology, which has broad prospects in treating environmental pollution and energy-saving [22]. Semiconducting materials can be excited by light irradiation and photoelectron-hole pairs can be generated in the lattices, which can improve both the internal conductivity for enlarged charge density and the oxidation kinetics on the surface [23]. Ren et al. first demonstrated the positive relationship between electroactive microorganisms and semiconducting iron/manganese oxides minerals at Karst areas in natural environments [24]. Moreover, enhancing the electron transfer process between a hematite/birnessite photoelectrode and different microorganisms under visible light was demonstrated, and the interaction between microbes and semiconducting minerals is becoming a hot spot in the interdisciplinary field of geomicrobiology [25-28]. Due to the abundant production, environmentally friendly attributes, and convenient access, abundant natural semiconducting minerals may be considered as alternatives for photocathode catalysts.

Although natural rutile was successfully utilized in MFCs [21], their wide band gap was a limiting factor. Exploring alternative semiconducting minerals with suitable bandgaps is crucial in the development of MFC photocatalysts with the efficiency required for large-scale field conditions. Very recently, tungstate was demonstrated to have a promising narrow band gap with fascinating applications in photocatalytic processes and optical fibers, owing to its low price, appropriate band gap, and strong redox capability [29-31]. Notably, natural wolframite is a common tungstate in nature, is an anionic catalyst. and is abundantly distributed in China. Natural semiconducting minerals are often doped with a variety of different elements, thus influencing their band gap. In this study, natural wolframite was used as a catalyst in a photocathode MFC system under near-neutral conditions. Both the mineralogical characteristics and the semiconducting properties of natural wolframite were systematically studied. The cell performances with different cathodes under dark/light conditions were discussed. Given the improvement of power output in this wolframite-MFC system, natural wolframite was demonstrated as an efficient and low-cost catalytic photocathode material in MFC, which had great potential applications in environmental treatment 
and large-scale field conditions in the future. Moreover, our study makes contributions to the rational and efficient use of mineral resources.

\section{Materials and Methods}

\subsection{Natural Wolframite Characterization}

Natural wolframite was collected and enriched in Shitouwa wolframite mineral deposit (Inner Mongolia, China). After gravitational separation and flotation, the wolframite was cleaned by ethanol and distilled water three times. Then, the samples were ground into powder and sieved into 400 mesh size grain with particle size below $45 \mu \mathrm{m}$. Scanning electron micrographs (SEM) of natural wolframite were obtained by using a scanning electron microscope (Hitachi S-4800, Tokyo, Japan) under a high voltage of $20 \mathrm{kV}$ and a pressure on $120 \mathrm{~Pa}$. The composition was analyzed by an energy dispersive X-ray spectrometer (EDX) (Bruker, QUANTAX 400, Billerica, MA, USA) and operated at $20 \mathrm{keV}$, and the elemental analysis mapping was carried out on the same equipment.

X-ray diffraction (XRD) was carried out by using an X-ray diffractometer ( $X^{\prime}$ pert Pro MPD, PANalytical Empyrean, Almelo, The Netherlands) equipped with $\mathrm{Cu}-\mathrm{K} \alpha$ irradiation $(\lambda=1.5406 \AA$ ). The patterns were recorded from 5 to $80^{\circ}(2 \theta)$ and the scanning speed was $4^{\circ} / \mathrm{min}$, which operated at $40 \mathrm{kV}, 40 \mathrm{~mA}$. The resulting XRD data were analyzed with the Powder Diffraction Standard (JCPDS) database.

Raman spectra were obtained by a Renishaw micro-Raman system (Renishaw inVia Reflex, Wotton-under-Edge, Gloucestershire, UK), which equipped with a long working-distance $50 \times$ objective and $532 \mathrm{~nm}$ laser. The laser intensity was $50 \%$ and diameter of beam spot was $1 \mu \mathrm{m}$. The spectral resolution was $1 \mathrm{~cm}^{-1}$ and all the Raman spectra were the average of ten successive scans $(20 \mathrm{~s}$ per scan) for higher signal-to-noise ratio. The frequency stability was checked by the spectrum of silicon.

UV-vis diffuse reflection spectra (DRS) were collected by a spectrometer (PerkinElmer UV/VIS/NIR Spectrometer, Lambda $750 \mathrm{~S}$, Waltham, MA, USA). The integrating sphere was from 200 to $1000 \mathrm{~nm}$ and with a slit width of $2.00 \mathrm{~nm}$ and $\mathrm{BaSO}_{4}$ (A.R., analytical reagent) was used as the reference. The concentration of soluble $\mathrm{Mn} / \mathrm{Fe}$ in cathode solution were determined by inductively coupled plasma-optical emission spectrometry (ICP-OES, SPECTRO, BLUE SOP).

\subsection{Preperation of Wolframite-Coated Cathode and MFCs Start-Up}

After the wolframite powder was prepared, wolframite-coated graphite cathodes $(3.0 \times 3.5 \times 0.5 \mathrm{~cm})$ were made according to the following process. Firstly, $400 \mathrm{mg}$ of wolframite was mixed with ethanol solution $(4 \mathrm{~mL})$ and $5 \%$ Nafion solution $(10 \mu \mathrm{L})$. Secondly, the mixture was ultrasonically dispersed for $10 \mathrm{~min}$ and then dropped onto the graphite surfaces, which were already polished by abrasive paper and cleaned by soaking in $\mathrm{HCl} / \mathrm{NaOH}$ as described in a previous study [19]. After air-drying, the wolframite-coated cathode was completed.

Self-made double chamber MFCs were applied in this experiment (Figure 1). As a part of the system, a common proton exchange membrane (PEM, 117, Dupont Co., Midland, MI, USA) was used to separate the two chambers. The volume of both anode and cathode chambers were $80 \mathrm{~mL}$. Anaerobic activated sludge was used as the inoculation bacteria for the anode chamber in the MFC and a carbon felt electrode was used as the bioanode. The anode chamber was filled with culture medium, containing: $0.13 \mathrm{~g} / \mathrm{L}$ of $\mathrm{KCl}, 0.2 \mathrm{~g} / \mathrm{L}$ of $\mathrm{MgSO}_{4}, 15 \mathrm{mg} / \mathrm{L}$ of $\mathrm{CaCl}_{2}, 0.31 \mathrm{~g} / \mathrm{L}$ of $\mathrm{NH}_{4} \mathrm{Cl}, 0.56 \mathrm{~g} / \mathrm{L}$ of $\left(\mathrm{NH}_{4}\right)_{2} \mathrm{SO}_{4}, 3.13 \mathrm{~g} / \mathrm{L}$ of $\mathrm{NaHCO}_{3}$, and $1 \mathrm{~g} / \mathrm{L}$ glucose. The cathode chamber was filled with $0.1 \mathrm{~mol} / \mathrm{L}$ $\mathrm{KCl}$ solution, which served as the electrolyte and bubbled with air. The cells were connected by an insulated copper wire and operated with an external resistance of $1000 \Omega$. All the MFCs were placed in biochemical incubator (LRH-250, Shanghai, China) and the temperature was maintained at $37^{\circ} \mathrm{C}$. The cathode light was provided by an external Light Emitting Diode (LED) lamp with an illumination intensity of $100 \mathrm{~mW} / \mathrm{cm}^{2}$. 


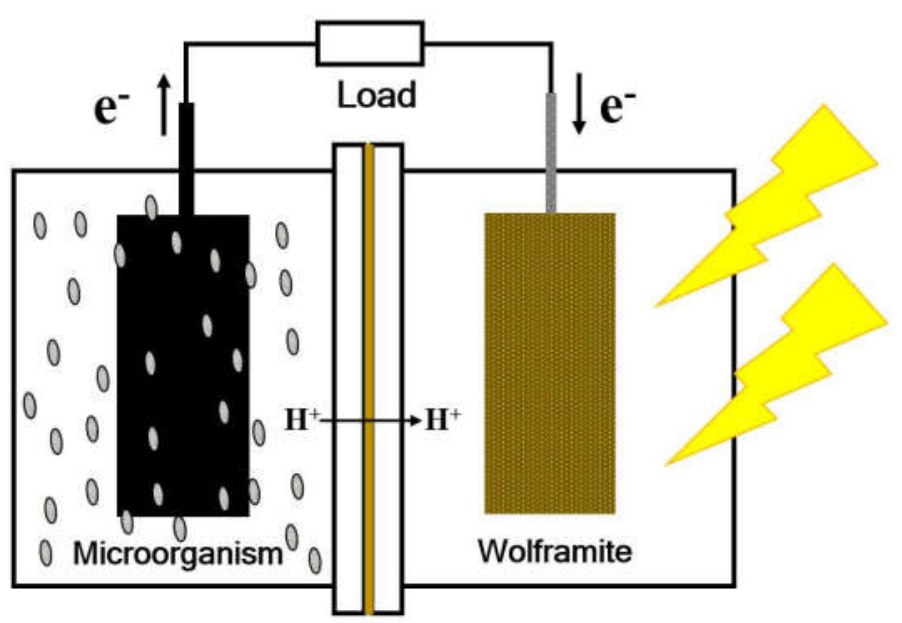

Figure 1. Schematic representation of the microbial fuel cell (MFC) with a natural wolframite-coated graphite cathode.

\subsection{Electricity and Electrochemical Measurements}

The performance of MFCs were evaluated by the output voltage recorded in a datalogger (ADC-16, Pico Technology, Cambridge, UK). Based on different resistance values, the polarization and power density curves were calculated. In addition, the anode and cathode potentials were recorded by independent digital voltmeter (UT-33B, Shenzhen, China) at the same time.

The photo-response of wolframite-coated graphite was measured in a quartz cube cell $(100 \mathrm{~mL})$ with a conventional three-electrode photoelectrochemistry system. Semiconducting wolframite-coated graphite, a platinum sheet, and a saturated calomel electrode (SCE, $0.245 \mathrm{~V}$ vs. normal hydrogen electrode) were used as the working, counter, and reference electrode, respectively. Linear sweep voltammetry (LSV) was performed in the electrolyte with $0.5 \mathrm{~mol} / \mathrm{L} \mathrm{Na}_{2} \mathrm{SO}_{4}$ under simulated standard sunlight illumination from a LED $\left(100 \mathrm{~mW} \cdot \mathrm{cm}^{-2}\right)$. The scan rate was $5 \mathrm{mV} / \mathrm{s}$ under oxygen $\left(\mathrm{O}_{2}\right)$ and nitrogen $\left(\mathrm{N}_{2}\right)$ conditions, respectively. Their values were recorded by an electrochemical workstation (CHI 760E, Shanghai Chenhua Instrument, Shanghai, China). All the potentials referred to the SCE electrode unless otherwise stated in the whole paper.

\section{Results and Discussion}

\subsection{Morphological and Structural Characterization of Wolframite}

Wolframite is a mineral of iron, manganese, and tungstate, which has a heavy grayish-black to brownish-black color. When ground into 400 mesh size grain, the color changed from black to brown. A typical SEM micrograph for a natural wolframite powder sample is shown in Figure 2a, which presents tabular and bladed crystals. Moreover, fracture surfaces and cleavage planes are prevalent on the surface of the natural wolframite, which are probably produced by the mechanical grinding. It is commonly known that the catalytic activity of catalysts is closely related to active sites. Therefore, much more active sites were provided by these fracture surfaces and cleavage planes, conferring greater potential to the processed wolframite as a low-cost catalyst than for wolframite synthetized with perfect crystal faces by complex methods. The EDX mapping demonstrated that $\mathrm{Mn}, \mathrm{Fe}, \mathrm{W}$, and $\mathrm{O}$ were especially enriched in the wolframite as shown in Figure $2 \mathrm{~b}-\mathrm{d}$. In addition, The EDS data reveal that the dominant elements are $\mathrm{W}, \mathrm{Mn}, \mathrm{Fe}$, and $\mathrm{O}$ and their contents were 61.71-66.07, 12.94-13.36, 5.23-6.11, and 14.88-19.7 wt\% respectively. The results were consistent with the chemical formula of wolframite, $(\mathrm{Fe}, \mathrm{Mn}) \mathrm{WO}_{4}$. 

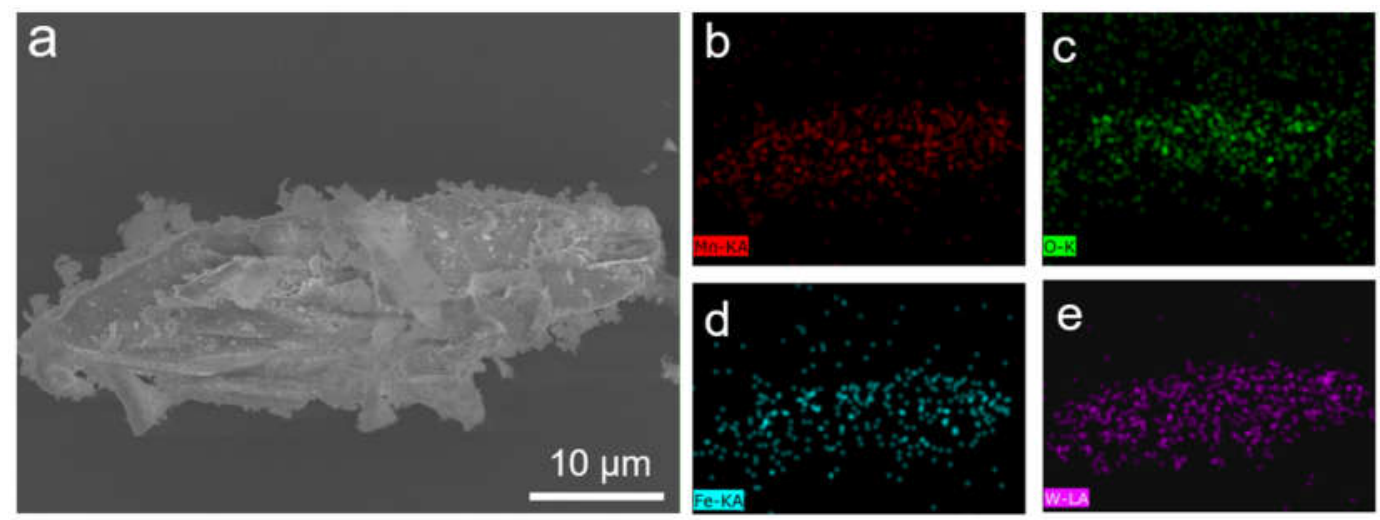

Figure 2. SEM image of natural wolframite (a) and energy dispersive X-ray spectrometry (EDX) mapping of different elements $(\mathbf{b}-\mathbf{e})$.

The XRD pattern of the natural wolframite sample is shown in Figure 3a. Although a mixture of phases was observed, wolframite was predominant. All diffraction peaks were perfectly indexed as pure structures of $\mathrm{MnWO}_{4}$ (JCPDS card no. 74-1491) and FeWO (JCPDS card no. 71-2391). These sharp diffraction peaks suggest great crystallinity of wolframite. Some peaks assigned to trace impurities could be detected and corresponded to quartz (JCPDS card no. 33-1161).
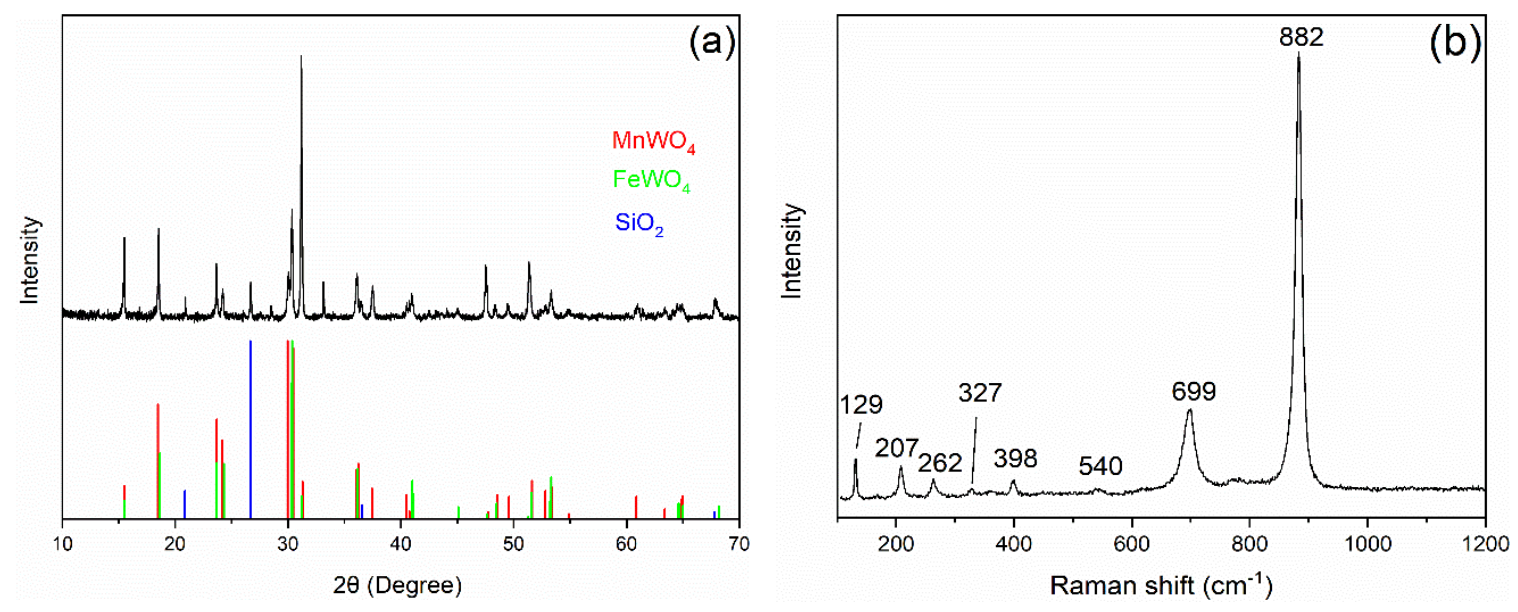

Figure 3. Powder XRD patterns (a) and Raman spectrum of natural wolframite (b).

Figure $3 b$ shows the Raman spectrum of natural wolframite. The bands at 129, 207, 262, 327, $398,540,699$, and $882 \mathrm{~cm}^{-1}$ correspond to the characteristic bands of wolframite, in agreement with previous studies [31-33]. In detail, the strongest sharp band at $882 \mathrm{~cm}^{-1}$ was assigned to the $v_{1}$ symmetric $A_{g}$ mode of terminal $W_{2}$. The band located at $699 \mathrm{~cm}^{-1}$ was attributed to antisymmetric bridging mode linking with the tungstate chain. The bands at $262 \mathrm{~cm}^{-1}$ and $207 \mathrm{~cm}^{-1}$ were assigned to the $v_{4}$ bending modes in the tungstate anion, while the band at $327 \mathrm{~cm}^{-1}$ is assigned to $v_{2}$ bending mode. The band at $125 \mathrm{~cm}^{-1}$ was induced by lattice vibration [31].

\subsection{Band Gap and Photocurrents}

Considering that the band structure plays a significant role in determining the photocatalytic activity of semiconducting materials, Figure 4a displays the UV-Vis absorption spectrum which shows a wide and strong absorption in the whole visible range of $400-700 \mathrm{~nm}$ by natural wolframite. Moreover, depending on the Kubelka-Munk formula, the optical absorption coefficient and the band gap energy (direct gap semiconductor) follow the Tauc plots as $(\alpha \mathrm{h} v)^{2}=\mathrm{A}\left(\mathrm{h} v-\mathrm{E}_{\mathrm{g}}\right)$, where $\alpha, \mathrm{h}, \mathrm{v}$, and $\mathrm{A}$ are absorption coefficient, Planck's constant, light frequency, and a constant, respectively [34]. As shown in 
Figure $4 \mathrm{a}$ (inserted picture), the estimated band gap $\left(\mathrm{E}_{\mathrm{g}}\right)$ was about $1.7 \mathrm{eV}$ as calculated by the intercept of the tangent. Previous study indicated that a hydrothermal synthetic $\mathrm{FeWO}_{4}$ photocatalyst had a band gap of $2.16 \mathrm{eV}$ [31] and synthesized $\mathrm{MnWO}_{4}$ had a band gap of $2.81 \mathrm{eV} \mathrm{[29].} \mathrm{However,} \mathrm{natural}$ wolframite had a narrower band-gap and considerably better optical absorption in the visible region than $\mathrm{MnWO}_{4}$ and $\mathrm{FeWO}_{4}$, which should produce more photoelectron/hole pairs under visible-light illumination. Therefore, we concluded that natural wolframite was a great photoactive material and improved photocatalytic performance should be conferred by its considerably broadened visible light response.
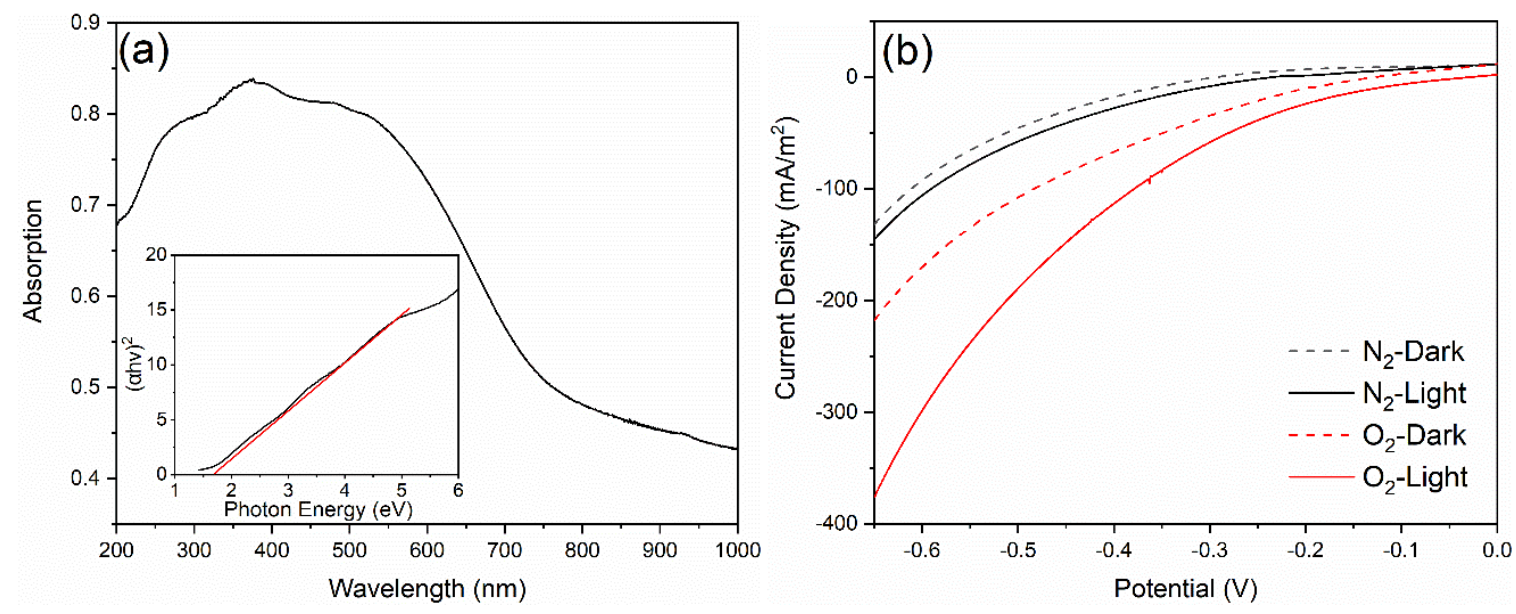

Figure 4. UV-Vis of natural wolframite (a) and linear sweep voltammetry (LSV) curves under dark/light conditions in $\mathrm{O}_{2} / \mathrm{N}_{2}(\mathbf{b})$.

For elucidating the photocatalytic activity of natural wolframite, electrochemical measurements corresponding to different applied potentials were performed by LSV dark/light curves under $\mathrm{N}_{2}$ and $\mathrm{O}_{2}$ conditions. Figure $4 \mathrm{~b}$ compares the dark/light LSV curve for a wolframite-coated graphite electrode at a potential of $-0.65-0.0 \mathrm{~V}$. With $\mathrm{N}_{2}$, the current densities were similar to each other, owing to the absence of an electron accepter. However, when $\mathrm{O}_{2}$ appears, higher current density was observed. Notably, a measurable photocurrent was observed. The average photocurrent density was $-319 \mathrm{~mA} \cdot \mathrm{m}^{-2}$ at $-0.6 \mathrm{~V}$ versus SCE, which was $175 \%$ greater than the dark current density $\left(-182 \mathrm{~mA} \cdot \mathrm{m}^{-2}\right)$ at the same voltage. The enhanced cathodic photocurrents indicated that the wolframite had p-type semiconducting nature. In addition, the value of the photocurrent was influenced by the potential change and the increment of current density was more significant with higher cathodic potentials. As a semiconducting mineral with a suitable band gap of $1.7 \mathrm{eV}$, wolframite absorbed visible light energy and generated photoexcited electrons/holes, suggesting the wolframite has great potential to be used as a cathode photocatalyst in MFCs.

\subsection{MFC Performance Analysis}

With the aim to evaluate the real efficiency of using natural wolframite as a MFC cathode photocatalyst, two sets of MFCs equipped with both a natural wolframite-coated graphite cathode and a normal graphite cathode were operated simultaneously. Their performances under dark/light conditions were quantified and compared via polarization curves and power density curves (Figure 5). The open circuit voltages (OCV) for the graphite cathode and the wolframite-coated cathode MFC were 489.2 and $520.2 \mathrm{mV}$, but their values increased to 496.3 and $575.3 \mathrm{mV}$ under light irradiation, as summarized in Table 1. Notably, the system resistance remarkably decreased from 1134.7 to $583.6 \Omega$, suggesting that the semiconducting wolframite successfully played the role of cathode photocatalyst in the MFC. 

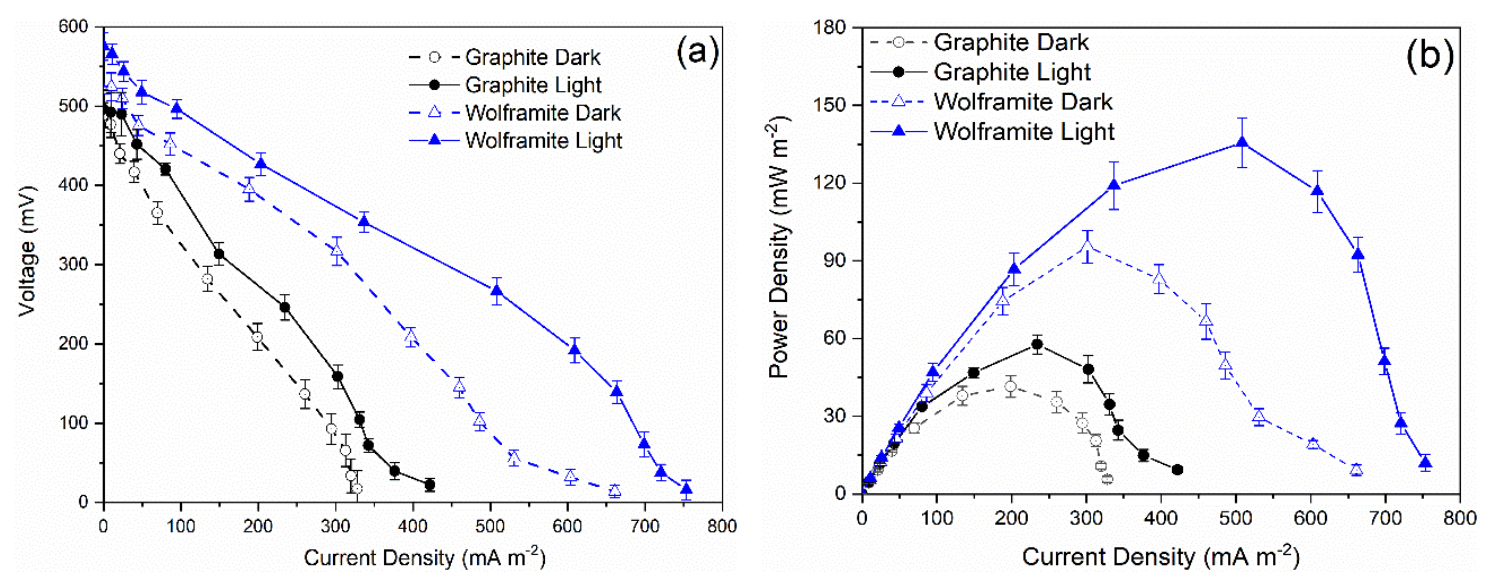

Figure 5. Polarization (a) and power density curves (b) of MFCs equipped with wolframite-coated graphite cathodes and bare graphite cathodes under dark/light conditions.

Table 1. The average electrical parameters of electron transfer in reaction systems.

\begin{tabular}{cccc}
\hline Cathode Condition & $\begin{array}{c}\text { Open Circuit Voltage } \\
(\mathbf{m V})\end{array}$ & $\begin{array}{c}\text { Maximum Output } \\
\text { Power }\left(\mathbf{m W} \cdot \mathbf{m}^{-\mathbf{2}}\right)\end{array}$ & $\begin{array}{c}\text { System Resistance } \\
(\boldsymbol{\Omega})\end{array}$ \\
\hline Graphite Dark & 489.2 & 41.47 & 1197.5 \\
Graphite Light & 496.3 & 57.74 & 1134.7 \\
Wolframite Dark & 520.2 & 95.51 & 754.1 \\
Wolframite Light & 575.3 & 135.57 & 583.6 \\
\hline
\end{tabular}

As far as the maximum power density is concerned, the highest value of $135.57 \mathrm{~mW} \cdot \mathrm{m}^{-2}$ was realized with a photo-wolframite cathode, while it was only $95.51 \mathrm{~mW} \cdot \mathrm{m}^{-2}$ without light irradiation (Figure $5 b$ ). However, the maximum power density of MFC with a bare graphite cathode was only 41.47 and $57.74 \mathrm{~mW} \cdot \mathrm{m}^{-2}$ under dark and light conditions, respectively. Compared with the photo-wolframite cathode and photo-graphite cathode, a nearly 2.4-fold increment of the efficiency was realized (Table 1). In an sterile control experiment, only a slight current was observed, which was even lower than $0.1 \mu \mathrm{A} \cdot \mathrm{cm}^{-2}$ with $100 \Omega$ resistance, suggesting that effective electron transfer could not establish between the anode culture medium and natural wolframite. The results demonstrated that semiconducting wolframite was a suitable candidate for cathode photocatalysts in MFC.

To gain a better understanding of the performance of wolframite photocathodes MFC, their power density was compared with MFCs in recent studies with different types of catalysts. For example, the maximum power density of a natural hematite-coated cathode MFC was $144.4 \pm 7.5 \mathrm{~mW} \cdot \mathrm{m}^{-2}$ [19], which was $45.4 \mathrm{~mW} \cdot \mathrm{m}^{-2}$ in a natural pyrrhotite-coated cathode MFC [20]. Moreover, manganese oxides nanoparticles and lead oxides were characterized as the cathode materials for MFCs, and the maximum power density of $\mathrm{MnO}_{x} / \mathrm{C}-\mathrm{MFC}$ was $161 \mathrm{~mW} \cdot \mathrm{m}^{-2}$ [16], and 22.1, 97.8, 82.6, and $78 \mathrm{~mW} \cdot \mathrm{m}^{-2}$ for $\alpha-\mathrm{MnO}_{2}, \beta-\mathrm{MnO}_{2}, \gamma-\mathrm{MnO}_{2}$, and $\mathrm{PbO}_{2}$-coated air cathode microbial fuel cells, respectively [15,18]. The maximum power density was much higher than $200 \mathrm{~mW} \cdot \mathrm{m}^{-2}$ when using a complex catalyst, such as nickel nanoparticle/C, phthalocyanine/C, copper-phthalocyanine/C, activated carbon, polytetrafluoroethylene, alumina/nickel nanoparticles-dispersed hierarchical structure of activated carbon microfibers or carbon nanofibers (CNFs) [35-37]. Notably, the value of maximum power density in our study was higher than that of the light- $\mathrm{Cu}_{2} \mathrm{O}$ cathode MFC $\left(77 \mathrm{~mW} \cdot \mathrm{m}^{-2}\right)$ and rutile-coated cathode $\left(120.3 \mathrm{~mW} \cdot \mathrm{m}^{-2}\right)$. In addition, no dissolved $\mathrm{Mn} / \mathrm{Fe}$ was detected in the cathode solution after ten days, suggesting the wolframite was stable. These comparison results demonstrated that wolframite should be considerable as a stable and available substitute for cathode photocatalysts, that is inexpensive, abundant, and without complex composites compared with other existing expensive artificial cathode materials. 


\subsection{Potential Study of Wolframite-Coated Cathode}

It should be pointed out that an enhanced power density, implying more efficient cathodic reactions, happened with the wolframite photocathode. Potential curves for four different types of photo/dark cathodes were obtained under actual operating conditions (Figure 6). Both anode and cathode potentials dropped gradually from the open circuit condition to short-circuit and a linear increase relationship was observed because of the domination of ohmic polarization. As far as the microbial anode was concerned, a similar potential of approximately $-455 \mathrm{mV}$ was recorded under open circuit conditions, which was consistent with previously reported MFCs [19]. Moreover, significant potential was presented when the current densities were limited by the electron transfer process on the electrode surface (Figure 5a). However, the turning position positively shifted from $340 \mathrm{~mA} \cdot \mathrm{m}^{-2}$ to $620 \mathrm{~mA} \cdot \mathrm{m}^{-2}$ when using the wolframite photocathode. In addition, higher current densities and more negative potentials, indicating enhanced anodic bio-activity, occurred in the anode chamber. As shown in Figure 5b, the cathode potentials were more positive when a wolframite coated cathode was used rather than a bare graphite electrode in the MFC. The cell voltage of the MFC was calculated by $E_{\text {cell }}=E_{\text {cathode }}-E_{\text {anode, }}$, therefore, the highest voltage was observed in the wolframite photocathode MFC system. It is worth mentioning that the potential of the wolframite-coated cathode was further increased under light irradiation (Figure $6 b$ ). A higher potential, indicating a better ability for receiving electrons, was observed for the wolframite photocathode. The results unambiguously demonstrated that a solar-driven MFC was successfully built based on the synergistic effect of a wolframite photocathode and bioanode. Such cathodic potentials and reaction properties demonstrated that the natural wolframite was an efficient cathode material for electron accepting in MFCs.
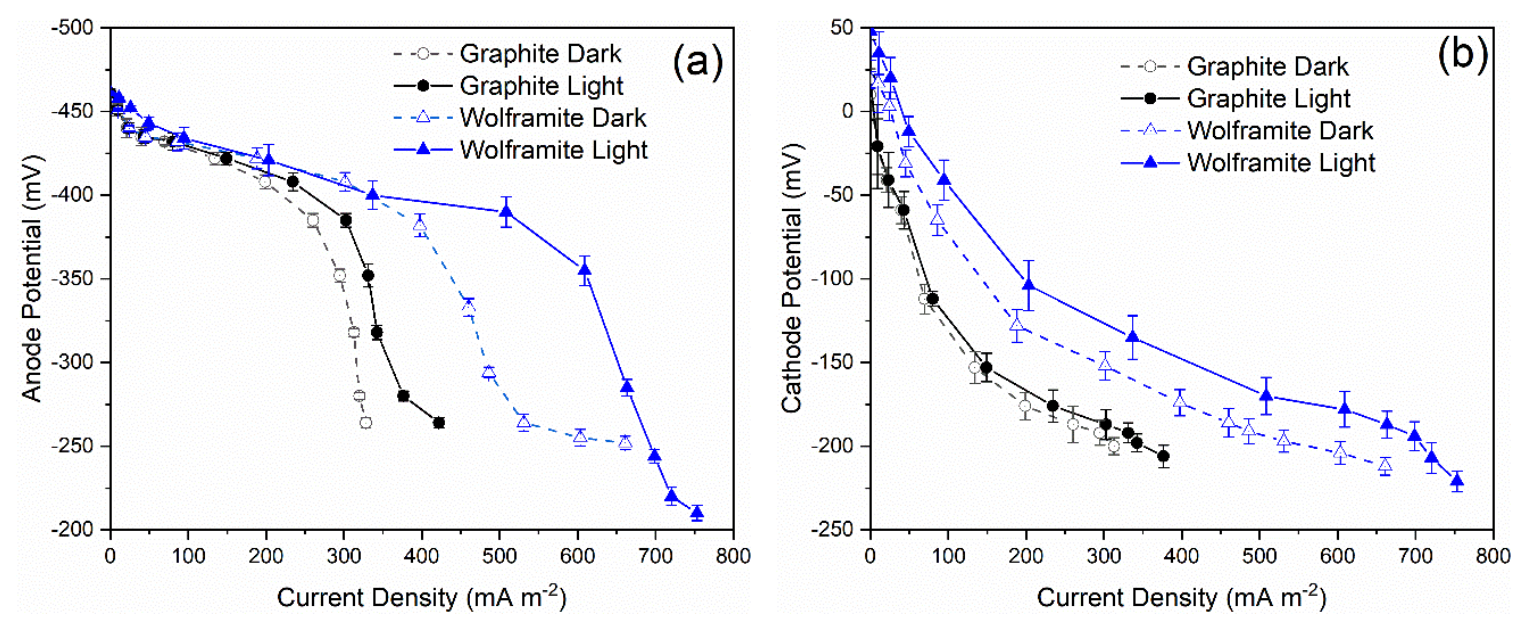

Figure 6. Anode potential curves (a) and cathode potential curves (b) with natural wolframite-coated graphite cathodes and bare graphite cathodes under dark/light conditions.

\subsection{Mechanisms of the Enhanced Performance of the Wolframite-Cathode MFC}

The primary mechanisms for the enhanced performance of wolframite photocathode MFC may be depicted as follows (Figure 7). At the anode, with the help of microbial metabolic activity for electricigens, an electrochemically active biofilm formed on the carbon felt, which oxidized glucose and produced electrons/protons. Subsequently, the protons permeated to the cathode chamber after passing the PEM. The bioelectrons were transferred from the anode chamber and were delivered to the cathode via the external circuit. Notably, wolframite is a p-type semiconducting mineral, and its semiconducting properties can be activated under light irradiation. Moreover, catalysts lower the overpotential of the cathode. On the surface of photocathode, the presence of abundant holes attracts electrons. These photoholes featured more positive potentials and were more easily combined with bioelectrons from the bioanode. This was consistent with the observation from cathode potential curves in Figure 6. More positive potentials forced the microorganisms to "work harder" and rapidly 
neutralize electrons that were transferred from the anode. Therefore, enhanced performance of the MFC was realized with the natural wolframite-coated photocathode.



Figure 7. Schematic representation of the enhanced performance of an MFC with a wolframite photocatalyst.

This novel wolframite photocathode MFC provided a cost-effective, environment-friendly, and energy clean cathode with long-term stability, and has broad prospects in various processes, including wastewater treatment and bioelectricity generation.

\section{Conclusions}

As a low-cost, natural, semiconducting mineral, natural wolframite was prepared and utilized as a photocathode catalyst to improve the cell performance of MFCs. Their morphological and structural characterization was studied by SEM, XRD, and Raman spectroscopy. Moreover, UV-vis spectroscopy and electrochemical techniques indicated that the natural wolframite had a band gap of $1.7 \mathrm{eV}$ and was a photoactive material that responded to visible light. Compared with a normal graphite cathode, the MFCs with a wolframite-coated cathode exhibited maximum power densities of 95.51 and $135.57 \mathrm{~mW} \cdot \mathrm{m}^{-2}$ under dark and light irradiation, respectively. These values were only 41.47 and $57.74 \mathrm{~mW} \cdot \mathrm{m}^{-2}$ with a typical graphite cathode. In addition, the system resistance was decreased from $1134.7 \Omega$ to $583.6 \Omega$, suggesting that wolframite was an ideal cathode catalyst in the MFC system. Results from our study demonstrated that using natural wolframite photocathodes in MFCs could enhance the performance of the MFCs. This low-cost and abundant natural semiconducting mineral has potential as an effective photocathode catalyst, and provides new directions for developing new MFCs in the future.

Author Contributions: J.S., A.L. and H.D. conceived and designed all the experiments; J.S., H.C., H.W. and H.D. performed the detailed experiments; J.S., A.L. and H.D. analyzed the experiment data; J.S. and H.D. wrote the paper.

Acknowledgments: This work was supported by the National Basic Research Program of China (973 Program, No. 2014CB846001) and the Natural Science Foundation of China (Grant Nos. 41230103, 41820104003 \& 91851208).

Conflicts of Interest: The authors declare no conflict of interest.

\section{References}

1. Li, W.W.; Yu, H.Q.; He, Z. Towards sustainable wastewater treatment by using microbial fuel cells-centered technologies. Energy Environ. Sci. 2014, 7, 911-924. [CrossRef]

2. Logan, B.E.; Rabaey, K. Conversion of wastes into bioelectricity and chemicals by using microbial electrochemical technologies. Science 2012, 337, 686-690. [CrossRef] [PubMed] 
3. Logan, B.E.; Hamelers, B.; Rozendal, R.; Schröder, U.; Keller, J.; Freguia, S.; Aelterman, P.; Verstraete, W.; Rabaey, K. Microbial fuel cells: Methodology and technology. Environ. Sci. Technol. 2006, 40, 5181-5192. [CrossRef] [PubMed]

4. Shi, L.; Dong, H.; Reguera, G.; Beyenal, H.; Lu, A.; Liu, J.; Yu, H.Q.; Fredrickson, J.K. Extracellular electron transfer mechanisms between microorganisms and minerals. Nat. Rev. Microbiol. 2016, 14, 651. [CrossRef] [PubMed]

5. Lovley, D.R. Live wires: Direct extracellular electron exchange for bioenergy and the bioremediation of energy-related contamination. Energy Environ. Sci. 2011, 4, 4896-4906. [CrossRef]

6. Oh, S.; Min, B.; Logan, B.E. Cathode performance as a factor in electricity generation in microbial fuel cells. Environ. Sci. Technol. 2004, 38, 4900-4904. [CrossRef]

7. Feng, L.; Yan, Y.; Chen, Y.; Wang, L. Nitrogen-doped carbon nanotubes as efficient and durable metal-free cathodic catalysts for oxygen reduction in microbial fuel cells. Energy Environ. Sci. 2011, 4, 1892-1899. [CrossRef]

8. Kim, J.R.; Kim, J.Y.; Han, S.B.; Park, K.W.; Saratale, G.D.; Oh, S.E. Application of Co-naphthalocyanine $(\mathrm{CoNPc})$ as alternative cathode catalyst and support structure for microbial fuel cells. Bioresour. Technol. 2011, 102, 342-347. [CrossRef]

9. Liu, Y.; Liu, H.; Wang, C.; Hou, S.-X.; Yang, N. Sustainable Energy Recovery in Wastewater Treatment by Microbial Fuel Cells: Stable Power Generation with Nitrogen-Doped Graphene Cathode. Environ. Sci. Technol. 2013, 47, 13889-13895. [CrossRef]

10. Lu, G.; Yang, H.; Zhu, Y.; Huggins, T.; Ren, Z.J.; Liu, Z.; Zhang, W. Synthesis of a conjugated porous Co(II) porphyrinylene-ethynylene framework through alkyne metathesis and its catalytic activity study. J. Mater. Chem. A 2015, 3, 4954-4959. [CrossRef]

11. Xia, X.; Zhang, F.; Zhang, X.; Liang, P.; Huang, X.; Logan, B.E. Use of Pyrolyzed Iron Ethylenediaminetetraacetic Acid Modified Activated Carbon as Air-Cathode Catalyst in Microbial Fuel Cells. ACS Appl. Mater. Interfaces 2013, 5, 7862-7866. [CrossRef] [PubMed]

12. Hao, L.; Zhang, B.; Tian, C.; Ye, L.; Shi, C.; Cheng, M.; Feng, C. Enhanced microbial reduction of vanadium(V) in groundwater with bioelectricity from microbial fuel cells. J. Power Source 2015, 287, 43-49. [CrossRef]

13. Clauwaert, P.; Van der Ha, D.; Boon, N.; Verbeken, K.; Verhaege, M.; Rabaey, K.; Verstraete, W. Open air biocathode enables effective electricity generation with microbial fuel cells. Environ. Sci. Technol. 2007, 41, 7564-7569. [CrossRef] [PubMed]

14. Weber, K.A.; Achenbach, L.A.; Coates, J.D. Microorganisms pumping iron: Anaerobic microbial iron oxidation and reduction. Nat. Rev. Microbiol. 2006, 4, 752-764. [CrossRef] [PubMed]

15. Lu, M.; Kharkwal, S.; Ng, H.Y.; Li, S. Carbon nanotube supported $\mathrm{MnO}_{2}$ catalysts for oxygen reduction reaction and their applications in microbial fuel cells. Biosens. Bioelectron. 2011, 26, 4728-4732. [CrossRef] [PubMed]

16. Roche, I.; Katuri, K.; Scott, K. A microbial fuel cell using manganese oxide oxygen reduction catalysts. J. Appl. Electrochem. 2010, 40, 13-21. [CrossRef]

17. Hosseini, M.G.; Ahadzadeh, I. A dual-chambered microbial fuel cell with $\mathrm{Ti} / \mathrm{nano}-\mathrm{TiO}_{2} / \mathrm{Pd}$ nano-structure cathode. J. Power Sources 2012, 220, 292-297. [CrossRef]

18. Morris, J.M.; Jin, S.; Wang, J.; Zhu, C.; Urynowicz, M.A. Lead dioxide as an alternative catalyst to platinum in microbial fuel cells. Electrochem. Commun. 2007, 9, 1730-1734. [CrossRef]

19. Ren, G.; Ding, H.; Li, Y.; Lu, A. Natural Hematite as a Low-Cost and Earth-Abundant Cathode Material for Performance Improvement of Microbial Fuel Cells. Catalysts 2016, 6, 157. [CrossRef]

20. Shi, J.; Zhao, W.; Liu, C.; Tao, J.; Ding, H. Enhanced Performance for Treatment of Cr(VI)-Containing Wastewater by Microbial Fuel Cells with Natural Pyrrhotite-Coated Cathode. Water 2017, 9, 979. [CrossRef]

21. Lu, A.; Li, Y.; Jin, S.; Ding, H.; Zeng, C.; Wang, X.; Wang, C. Microbial fuel cell equipped with a photocatalytic rutile-coated cathode. Energy Fuels 2009, 24, 1184-1190. [CrossRef]

22. Chen, X.B.; Shen, S.H.; Guo, L.J.; Mao, S. Semiconductor-based photocatalytic hydrogen generation. Chem. Rev. 2010, 110, 6503-6570. [CrossRef] [PubMed]

23. Grätzel, M. Photoelectrochemical cells. Nature 2001, 414, 338-344. [CrossRef] [PubMed]

24. Ren, G.; Yan, Y.; Sun, M.; Wang, X.; Wu, X.; Li, Y.; Lu, A.; Ding, H. Considerable Bacterial Community Structure Coupling with Extracellular Electron Transfer at Karst Area Stone in Yunnan, China. Geomicrobiol. J. 2018, 35, 424-431. [CrossRef] 
25. Lu, A.; Li, Y.; Jin, S.; Wang, X.; Wu, X.; Zeng, C.; Li, Y.; Ding, H.; Hao, R.; Lv, M.; et al. Growth of non-phototrophic microorganisms using solar energy through mineral photocatalysis. Nat. Commun. 2012, 3, 768. [CrossRef] [PubMed]

26. Ren, G.; Sun, Y.; Sun, M.; Li, Y.; Lu, A.; Ding, H. Visible Light Enhanced Extracellular Electron Transfer between a Hematite Photoanode and Pseudomonas aeruginosa. Minerals 2017, 7, 230. [CrossRef]

27. Qian, F.; Wang, G.; Li, Y. Solar-driven microbial photoelectrochemical cells with a nanowire photocathode. Nano Lett. 2010, 10, 4686-4691. [CrossRef] [PubMed]

28. Ren, G.; Sun, Y.; Ding, Y.; Lu, A.; Li, Y.; Wang, C.; Ding, H. Enhancing extracellular electron transfer between Pseudomonas aeruginosa PAO1 and light driven semiconducting birnessite. Bioelectrochemistry 2018, 123, 233-240. [CrossRef] [PubMed]

29. He, H.Y.; Huang, J.F.; Cao, L.Y.; Wu, J.P. Photodegradation of methyl orange aqueous on $\mathrm{MnWO}_{4}$ powder under different light resources and initial pH. Desalination 2010, 252, 66-70. [CrossRef]

30. Vosoughifar, M. Preparation, characterization, and morphological control of $\mathrm{MnWO}_{4}$ nanoparticles through novel method and its photocatalyst application. J. Mater. Sci. Mater. Electron. 2017, 28, 2135-2140. [CrossRef]

31. Gao, Q.; Liu, Z. $\mathrm{FeWO}_{4}$ nanorods with excellent UV-Visible light photocatalysis. Prog. Nat. Sci. Mater. Int. 2017, 27, 556-560. [CrossRef]

32. Choi, W.S.; Taniguchi, K.; Moon, S.J.; Seo, S.S.; Arima, T.; Hoang, H.; Yang, I.S.; Noh, T.W.; Lee, Y.S. Electronic structure and anomalous band-edge absorption feature in multiferroic $\mathrm{MnWO}_{4}$ : An optical spectroscopic study. Phys. Rev. B 2010, 81, 205111. [CrossRef]

33. Hu, W.; Zhao, Y.; Liu, Z.; Dunnill, C.; Gregory, D.H.; Zhu, Y. Nanostructural evolution: From one-dimensional tungsten oxide nanowires to three-dimensional ferberite flowers. Chem. Mater. 2008, 20, 5657-5665. [CrossRef]

34. Liu, K.; Li, J.; Yan, X.; Shi, W. Synthesis of Direct Z-Scheme $\mathrm{MnWO}_{4} / \mathrm{g}-\mathrm{C}_{3} \mathrm{~N}_{4}$ Photocatalyst with Enhanced Visible Light Photocatalytic Activity. Nano 2017, 12, 1750129. [CrossRef]

35. Ghasemi, M.; Daud, W.R.W.; Rahimnejad, M.; Rezayi, M.; Fatemi, A.; Jafari, Y.; Somalu, M.R.; Manzour, A. Copper-phthalocyanine and nickel nanoparticles as novel cathode catalysts in microbial fuel cells. Int. J. Hydrogen Energy 2013, 38, 9533-9540. [CrossRef]

36. Dong, H.; Yu, H.; Wang, X.; Zhou, Q.; Feng, J. A novel structure of scalable air-cathode without Nafion and Pt by rolling activated carbon and PTFE as catalyst layer in microbial fuel cells. Water Res. 2012, 46, 5777-5787. [CrossRef] [PubMed]

37. Gupta, S.; Yadav, A.; Verma, N. Simultaneous Cr(VI) reduction and bioelectricity generation using microbial fuel cell based on alumina-nickel nanoparticles-dispersed carbon nanofiber electrode. Chem. Eng. J. 2017, 307, 729-738. [CrossRef]

(c) 2018 by the authors. Licensee MDPI, Basel, Switzerland. This article is an open access article distributed under the terms and conditions of the Creative Commons Attribution (CC BY) license (http://creativecommons.org/licenses/by/4.0/). 